УДК: $339.727 .22: 339.54$

ББК: $65.263+65.428$

КОМПЛЕКСНЫЙ ПОДХОД К ФОРМИРОВАНИЮ ПОЛИТИКИ ПРИВЛЕЧЕНИЯ ПРЯМЫХ ИНВЕСТИЦИЙ И ВНЕШНЕТОРГОВОЙ ПОЛИТИКИ

\author{
Н. С. ШАЛУПАЕВА \\ nshalupaeva@mail.ru \\ старший преподаватель \\ Гомельский государственный университет имени Ф. Скорины \\ Гомель, Республика Беларусь
}

Обоснован комплексный подход к формированию политики привлечения прямых инвестиций и внешнеторговой политики, выявлен возможный синергетический эффект между ними и эффект нивелирования друг друга. В этих иелях исследованы влияние основных инструментов торговой политики государства на внешнеторговые эффекты прямых иностранных инвестиций, в том числе политики региональной торговой интеграции, а также внешнеторговые эффекты инвестиционной политики.

Ключевые слова: прямые иностранные инвестиции, внешняя торговля, инвестиционная политика, внешнеторговая политика

\title{
INTEGRATED APPROACH TO THE FORMATION OF FOREIGN DIRECT INVESTMENTS AND FOREIGN TRADE POLICIES
}

\author{
N. S. SHALUPAYEVA \\ senior lecturer \\ F. Scorina Gomel State University \\ Gomel, Republic of Belarus
}

An integrated approach to formation of foreign trade policy andforeign direct investments policy is formulated, the possible synergetic effect between them and effect of leveling each other are revealed in the article. For this purpose, influence of the main trade policy instruments, including policy of regional trade integration, on the foreign direct investments trade effects and also the foreign trade effects of the investment policy are investigated.

Keywords: foreign direct investments, foreign trade, investment policy, foreign trade policy, policy of targeting

\section{ВВЕДЕНИЕ}

Традиционно национальные внешнеторговая политика и политика привлечения прямых иностранных инвестиций (ПИИ) рассматриваются отдельно друг от друга, нередко ориентированы на различные цели и определяются и реализуются отдельными, не связанными друг с другом органами и агентствами. Очевидно, это противоречит современным тенденциям роста взаимосвязи ПИИ и международной торговли и может спровоцировать ситуацию, когда торговая и инвестиционная политики снижают эффективность либо даже нейтрализуют друг друга, что может привести к упущению возможностей развития. Напротив, их координация и взаимообусловленность может создать синергетический эффект, который увеличит их эффективность в достижении поставленных целей экономического роста. 
Необходимость комплексного подхода к проведению внешнеторговой и инвестиционной политики продиктована не только растущей взаимозависимостью потоков ПИИ и международной торговли, но и наличием объективной взаимосвязи между самими политиками. С одной стороны, инвестиционная политика осуществляется в рамках национальной внешнеэкономической стратегии развития: ее специфика зависит как от содержания и целей преобладающей внешнеэкономической стратегии (политики импортозамещения или ориентации на экспорт), так и от соотношения между видами внешнеторговой политики (протекционизмом и либерализацией). С другой стороны, регулирование таможенно-тарифной сферы является одним из направлений государственной политики регулирования ПИИ. Так, классификация мер государственной политики регулирования ПИИ, разработанная ОЭСР, включает пять групп мер: меры торговой политики; меры стимулирования ПИИ; ограничительные меры для иностранных инвестиций; меры в отношении предприятий, которые осуществляют ограничительную деловую практику; меры по стимулированию и ограничению, которые применяются странами-экспортерами капитала [1, с. 264].

Вопросами влияния внешнеторговой политики на потоки ПИИ занимались ряд зарубежных ученых: С. Хаймер, Т. Хорст, Дж. Маркузен, Я. Бхагвати, Р. Бречер, М. Мотта, Дж. Гроссман, И. Хелпман, Л. Ванг, Т. Бертран, Ф. Флэттерс, Р. Финстр, А. Швайнбергер, Р. Финдли, Дж. Ниари, Ф. Руанэ; среди отечественных ученых можно выделить Е. Семак, И. Турлай. Вопросы комплексного подхода к формированию внешнеторговой политики и политики регулирования ПИИ, а также влияния их инструментов на потоки инвестиций исследуются и международными экономическими организациями, прежде всего, ЮНКТАД и ВТО [2]. Вместе с тем до настоящего времени системного исследования взаимозависимости ПИИ и внешнеторговой политики страны, в особенности в проекции на экономику Республики Беларусь, не представлено ни в зарубежной, ни в отечественной литературе. Воздействие внешнеторговой политики н закономерности взаимосвязи ПИИ и внешней торговли изучено мало, еще меньше изучены внешнеторговые эффекты инвестиционной политики, а также вопросы взаимосвязи внешнеторговой и инвестиционной политики, взаимоусиления или нивелирования эффектов друг друга. В связи с этим целью статьи является обоснование комплексного подхода к формированию политики привлечения ПИИ и внешнеторговой политики, который предполагает установление воздействия инструментов данных политик на внешнеторговые эффекты ПИИ, выявление возможного синергетического эффекта между ними и эффекта нивелирования друг друга.

\section{РЕЗУЛЬТАТЫ И ИХ ОБСУЖДЕНИЕ}

Для формирования согласованных политики привлечения ПИИ и внешнеторговой политики необходимо понимание внешнеторговых эффектов инвестиционной политики, с одной стороны, а также механизма воздействия торговой политики на внешнеторговые эффекты ПИИ*, с другой.

Воздействие торговой политики на внешнеторговые эффекты ПИИ.

С одной стороны, внешнеторговая политика является одним из главных факторов при принятии решения об инвестировании в ту или иную страну [3], т. е. определяет количественные эффекты ПИИ. С другой стороны, торговая политика определяет

*Под внешнеторговыми эффектами ПИИ автор понимает количественные или качественные изменения в экспортно-импортных операциях страны, вызванные прямо или косвенно деятельностью компаний с участием ПИИ. 
степень и направления влияния ПИИ на экономическое развитие принимающей страны, особенно в части передачи технологий и налаживания связей с национальными поставщиками, т.е. влияет на качественную сторону ПИИ.

1. Политика регулирования импорта в стране-реципиенте ПИИ:

a) Тарифные и нетарифные барьеры для импорта товаров. Высокие тарифы на импорт могут способствовать притокугоризонтальных ПИИ, однако эмпирические исследования показывают, что если ранее величина импортных тарифов находилась в положительной корреляции с ПИИ, то сейчас между ними наблюдается обратная зависимость. В то же время торговая открытость позитивно коррелирует с ПИИ в большинстве эмпирических исследований, причем она наиболее тесно связана с ПИИ, чем любой другой фактор [4, с. 93]. Эти изменения вызваны развитием международного производства, когда ТНК выбирают страну инвестирования для того, чтобы выиграть на разнице в издержках и на эффекте масштаба, в результате высокие торговые барьеры, ограничивающие возможности для фрагментации производства, могут снизить конкурентные преимущества стран в привлечении ПИИ [5].

б) Барьеры для импорта промежуточных и инвестиционных товаров могут снизить конкурентоспособность ориентированной на экспорт деятельности (особенно филиалов ТНК и в отраслях, не привязанных к источникам сырья), которая в настоящее время во многом зависит от импортируемых инвестиционных и промежуточных товаров мирового качества и по мировым ценам. Высокие импортные тарифы могут поощрять иностранные компании использовать национальных поставщиков, однако это влечет за собой ряд издержек. Во-первых, в случае если национальные фирмы недостаточно конкурентоспособны, иностранные инвесторы могут принять решение инвестировать в другую страну. Это объясняет, почему импортозамещающие стратегии большинства стран оказались неэффективными и в конечном итоге отменены. Вовторых, эффективные связи ПИИ и национальных производителей возможны, когда пошлины на импорт промежуточных и инвестиционных товаров низкие, и филиалы ТНК полностью интегрированы в ГПС, так как современные технологи часто воплощены в импортируемых промежуточных товарах, что обеспечивает доступ местных фирм к современным технологиям. Таким образом, высокие барьеры на импорт технологий или производственных ресурсов могут повредить конкурентоспособности экспорта не только иностранных, но и отечественных фирм, воспрепятствовав распространению внешних эффектов от ТНК в экономике принимающей страны [5].

в) Регулирование торговли услугами. Развитие системы международного производства привело к значительному росту внутрифирменной торговли услугами, что делает либерализацию торговли в сфере услуг ключевым моментом для привлечения экспорто ориентированных ПИИ, прежде всего, ориентированных на эффективность. Однако следует отметить, что либерализация торговли в сфере услуг должна быть скоординирована с политикой регулирования ПИИ в сферу услуг.

г) Упрощение торговых процедур стимулирует ПИИ и развитие внешней торговли. ПИИ, ориентированные на эффективность, которые влекут за собой рост импорта промежуточных и инвестиционных товаров за счет развития внутрифирменной торговли в рамках вертикально интегрированных ТНК, требуют упрощения таможенных и административных процедур [5]. В результате повышение эффективности таможенного администрирования, в особенности сокращение времени на прохождение таможенных процедур, будет способствовать росту притока экспорто ориентированных ПИИ в страну. Примером может послужить опыт Коста-Рики в отношении компании Intel.

2. Политика регулирования экспорта в стране-реципиенте ПИИ: 
a) Тарифные и нетарифные ограничения экспорта, введение экспортного контроля. Политика ограничения экспорта в стране-реципиенте ПИИ, например, лицензирование, очевидно негативно влияет на приток экспорто ориентированных ПИИ (вертикальных, экспортно-платформенных и комплексных), являющихся наиболее выгодными с позиции развития внешней торговли принимающей экономики, однако никак не влияет на приток ПИИ, ориентированных на внутренний рынок. В результате может возрасти импорт страны-реципиента и однозначно упадет экспорт (либо потенциально не увеличится).

б) Стимулирование экспорта поощряет приток экспорто ориентированных ПИИ. В то же время практика показывает, что экспорто ориентированная стратегия развития может быть и «нейтральной», ей достаточно быть направленной на устранение торговых барьеров, при этом не обязательно применение государственных мер поддержки экспорта для привлечения экспорто ориентированных ПИИ [3]. Финансирование экспорта может негативно сказаться на экспорто ориентированных ПИИ в тех случаях, когда субсидии являются заменой девальвации национальной валюты в случае проведения страной протекционистской торговой политики с целью компенсировать производителям вызванную завышенным курсом национальной валюты потерю их экспортной конкурентоспособности.Страны, как правило, отличающиеся более жестким регулированием ПИИ, создают специальные экономические зоны (СЭЗ), способствующие развитию экспортной деятельности. СЭЗ являются своего рода формой селективной либерализации внешней торговли, что позволяет даже при реализации стратегии импортозамещения привлечь экспорто ориентированные ПИИ. В мировой практике существуют примеры успешной реализации политики создания СЭЗ как механизма привлечения экспорто ориентированных ПИИ, особенно в Восточной Азии, однако в целом результаты их функционирования трудно оценить однозначно. СЭЗ являются исключением из экономического режима, действующего в стране, в связи с чем внешние эффекты ПИИ, как правило, незначительны и ограничиваются СЭЗ [5], что снижает либо исключает косвенные внешнеторговые эффекты ПИИ. Кроме того, резиденты СЭЗ часто импортируют все комплектующие, в результате во многих случаях СЭЗ содействуют не только увеличению экспорта, но и значительному росту импорта [6, с 14]. В странах Восточной Азии СЭЗ не были единственным инструментом развития экспорта: эти государства проводили активную индустриальную политику, направленную на развитие отечественных предприятий, поддерживали низкую инфляцию и стабильный валютный курс, способствовали росту квалификации рабочей силы [7, с. 23].

в) Регулирование экспорта услуг. В настоящее время экспорто ориентированные ПИИ в сферу услуг значительно увеличились, многие фирмы в развивающихся странах, работающие по контрактам аутсорсинга с компаниями из развитых стран, являются компаниями с участием ПИИ. В связи с этим либерализация экспорта услуг является критически важным элементом внешнеторговой политики стран.

г) Таможенные и административные процедуры при экспорте. Как и в случае с импортом, стоимость и скорость прохождения таможенных процедур и системы таможенной очистки товаров повышают привлекательность страны для экспорто ориентированных ПИИ, прежде всего, ПИИ, ориентированных на эффективность.

3. Политика регулирования импорта в стране-доноре:

a) Импортный протекционизм в стране-доноре очевидно ограничивает приток вертикальных ПИИ (экспортно-платформенных для страны базирования) в другие страны. Однако на этот тип ПИИ приходится незначительная часть мировых ПИИ, еще меньшая их доля приходится на конкретные страну-реципиента и страну-донора. 
б) Регулирование доступа на рынок для продукции и услуг из развивающихся стран. Привлечение экспорто ориентированных ПИИ в страну зависит от режима доступа для ее продукции и услуг на рынки развитых стран или другие емкие рынки. Одним из наиболее распространенных способов регулирования доступа на рынок является тарифная эскалация, которая может мешать диверсификации и росту экспорта товаров с более высоким уровнем добавленной стоимости из развивающихся стран, что дестимулирует экспорто ориентированные ПИИ в них. Барьеры, применяемые развивающимися странами, могут быть еще более губительны для экспортоориентированных ПИИ. Во-первых, они в среднем выше, чем в развитых странах. Во-вторых, барьеры между развивающимися странами сужают региональные рынки сбыта, что негативно сказывается на привлечении экспортно-платформенных ПИИ и сокращает возможности для развития ориентированных на эффективность ПИИ из самих развивающихся стран. В-третьих, исследования показывают, что торговля между развивающимися странами приносит им больше выгод, чем с развитыми [3].

в) Меры защиты внутреннего рынка. Антидемпинговые, компенсационные и защитные меры разрешены ВТО, однако могут быть существенным препятствием для экспорта. Как показывает практика, эти меры вводятся в отношении продукции с высокой добавленной стоимостью, тем самым препятствуя увеличению добавленной стоимости, созданной и экспортированной развивающимися странами, что сокращает приток экспорто ориентированных ПИИ. Кроме того, подобные меры вносят элемент неопределенности касательно доступа на рынок для продукции, экспортированной из страны-реципиента, и даже угроза таких мер может способствовать изъятию ПИИ.

г) Торговые преференции стимулируют экспорто ориентированные ПИИ и увеличивают вероятность ПИИ в страны, которым предоставлен преференциальный доступ, однако эти меры могут значительно исказить конкурентные преимущества стран мира. Кроме того, торговыепреференции и преференциальные торговые соглашения в сочетании с правилами определения страны происхождения товаров могут иметь протекционистский эффект и ведут к росту ПИИ в производство промежуточной продукции в регион. Чем более строгими являются правила определения происхождения товаров, тем более очевидна необходимость иностранного инвестора в размещении всего цикла производственного процесса в регионе, что будет способствовать росту экспортно-платформенных и комплексно-вертикальных ПИИ в страны-члены. Вместе с тем, строгие правила определения страны происхождения товара могут дестимулировать ориентированные на эффективность ПИИ, если они не позволяют компаниям импортировать товары из наиболее эффективных источников [6, с. 16]. Торговые преференции, предоставляемые развивающимся странам, могут быть подорваны правилами определения страны происхождения, так как большинство продукции, экспортированной из них, не будет попадать под преференции, если они включают сырье из третьих стран.

4. Политика регулирования экспорта в стране-доноре:

a) Экспортные субсидии. Экспортные субсидии в стране-доноре в отношении готовых товаров снижают стимулы для осуществления экспорто ориентированных ПИИ, однако экспортные субсидии на инвестиционные и промежуточные товары могут привести к росту ПИИ (как импортозамещающих, так и экспорто ориентированных), т.к. они увеличивают уровень рентабельности ПИИ в принимающей стране.

б) Экспортный контроль и ограничения могут препятствовать трансферу технологий в принимающую страну, а, следовательно, дестимулировать приток ПИИ в высокотехнологичные отрасли развивающихся и переходных экономик. С другой стороны, экспортный контроль и ограничения в стране-доноре могут стимулировать экспорто ориентированные ПИИ в принимающие страны, которые иначе были бы осуществлены 
в стране-доноре. Таким образом, ограничения экспорта в стране-доноре влияют на потоки ПИИ таким же образом, как и протекционизм в стране-реципиенте, однако в значительно меньшей степени.

В целом можно заключить, что внешнеторговая политика стран-доноров в значительно меньшей степени влияет на потоки ПИИ и их внешнеторговые эффекты, нежели торговая политика принимающих стран [3], которая является критически важной для регулирования объемов и структуры потоков ПИИ [8, с. 19].

Существенное воздействие на потоки ПИИ и их внешнеторговые эффекты оказывает политика региональной торговой интеграции. Результаты исследования МВФ, опубликованного в 2004 г., показывают значительный положительный эффект роста размера внутрирегионального рынка на объемы ПИИ [5]. Одновременно современные региональные торговые соглашения (РТС) демонстрируют незначительную связь с ростом горизонтальных ПИИ [3]. Таким образом, увеличение размера рынка внутри РТС приводит к росту притока экспортно-платформенных и комплексных ПИИ в регион. Однако в случае, если в результате подписания РТС в ряде стран-участниц возрастает уровень протекционизма во внешней торговле в отношении третьих стран, увеличатся как межрегиональные экспортно-платформенные, так и горизонтальные ПИИ. Что касается внутрирегиональных ПИИ, то их объемы нередко падают после подписания PTC, так как снижение или устранение внутренних торговых барьеров приводит к снижению или даже изъятию импортозамещающих ПИИ [9], ориентированных ранее на преодоление этих барьеров. Вместе с тем, РТС облегчает вертикальные, экспортноплатформенные и комплексные ПИИ, осуществляемые с целью создания экспортной платформы. Таким образом, воздействие подписания РТС на межрегиональные ПИИ проявляется в ростеуровня горизонтальных, экспортно-платформенных и комплексных межрегиональных ПИИ и спаде объемов вертикальных ПИИ, на внутрирегиональные ПИИ - в снижении уровня горизонтальных ПИИ и росте вертикальных, экспортноплатформенных и комплексных ПИИ. Таким образом, внешнеторговые эффекты ПИИ в результате создания РТС целесообразно разделить на два уровня:

1) Страновой уровень. Внешнеторговые эффекты ПИИ в результате создания РТС будут положительные для стран интеграционной группировки, имеющих наибольшие конкурентные преимущества, за счет роста притока в них внерегиональных и внутрирегиональных экспорто ориентированных ПИИ, к которым автором отнесены вертикальные, экспортно-платформенные и комплексно-вертикальные ПИИ, и соответственноотрицательные для менее привлекательных для инвесторов государств.

2) Региональный уровень. РТС способствуют росту внеинтеграционной торговли, прежде всего, за счет привлечения экспортно-платформенных и комплексных ПИИ, обусловленного возросшим внутрирегиональным рынком сбыта и ростом уверенности в стабильности торговых связей, а также росту внутриинтеграционной торговли за счет реструктуризации производственных процессов внутри региона [10].

\section{Внешнеторговые эффекты инвестиционной политики.}

В целях исследования инвестиционные меры, в наибольшей степени влияющие на внешнеторговые эффекты ПИИ, разделены на три категории [10]:

1. Требования к эффективности деятельности предприятий с иностранными инвестициями, обязательные к исполнению:

a) Требования содержания местных компонентов. Главным эффектом этих требований на внешнюю торговлю принимающей страны является замещение импорта соответствующих видов сырья и компонентов, что и является их целью. Однако подобные требования могут способствовать снижению экспортной конкурентоспособности готовой продукции иностранных филиалов из-за меньшей эффективности местных постав- 
щиков, что в итоге приведет либо к сокращению экспорто ориентированных ПИИ, либо к уменьшению экспорта уже существующих в стране компаний с иностранными инвестициями. Еще одним внешнеторговым эффектом этих требований является рост импорта готовой продукции компаниями-конкурентами, так как их выполнение, как правило, влечет дополнительные затраты у иностранных филиалов. Принимающая страна устанавливает требования на содержание местных компонентов так же с целью налаживания связей между национальными и иностранными фирмами. Однако, рост издержек производства сокращает объем производства иностранных компаний, а значит, и уровень спроса на местные компоненты и запасные части, в результате чего ожидаемые преимущества от укрепления связей между национальными и зарубежными фирмами не материализуются [5]. Таким образом, требования использования местного компонента эквивалентны пошлинам, взимаемым с импортных товаров.

б) Требования в отношении расширения экспорта товаров. С одной стороны, эти меры действительно могут стимулировать рост экспорта иностранных филиалов, однако они сами по себе вряд ли будут способствовать экспортной ориентации ПИИ. Кроме того, для ПИИ, ориентированных на внутренний рынок, такие требования, как правило, влекут дополнительные затраты, т.к. вынуждают направлять часть прибыли, полученной на внутреннем рынке, на выполнение экспортных требований, хотя экспорт изначально не был их целью. В результате стоимость продукции, поступающей на внутренний рынок, возрастает, что в свою очередь увеличивает импорт соответствующей готовой продукции в страну [10]. Выполнение требований экспорта может также стимулировать импорт сырья и комплектующих. Кроме того, эти требования могут способствовать замещению экспорта других товаров [1, с. 258], в том числе экспорта национальных производителей.

в) Требования сбалансированности торговли по сути являются комбинацией двух предыдущих. Таким образом, они сокращают импорт промежуточных товаров, увеличивают экспорт готовой продукции за счет замещения экспорта других товаров $[1$, c. 260], в том числе экспорта национальных производителей. Выполнение этих требований влечет за собой дополнительные затраты для компаний с иностранными инвестициями, что-либо сокращает ПИИ, либо увеличивает импорт готовой продукции [10], внешнеторговые эффекты при этом будут определяться типом этих упущенных ПИИ.

г) Требования, регулирующие долю иностранного капитала в уставном фонде предприятия. Влияние этих требований на деятельность иностранных компаний мало изучено в экономической литературе, однако можно утверждать, что в случае обязательного наличия национального капитала в уставном фонде, возможное некоммерческое и недобросовестное поведение иностранных партнеров менее вероятно (трансфертное ценообразование, приоритетные закупки промежуточных и инвестиционных товаров в стране-доноре, регулирование экспортных потоков и др.). С дугой стороны, именно по причине ограничения автономии иностранных инвесторов, последние могут отказаться от инвестирования в данную страну. Внешнеторговые эффекты при этом будут определяться типом этих упущенных ПИИ.

д) Требования в отношении трансфера технологий. С одной стороны, данные требования действительно могут способствовать активизации передачи технологий от иностранных компаний национальным. С другой стороны, использование иностранными компаниями новейших технологий не обеспечивает гарантированного роста экспорта, а затраты могут оказаться выше, чем при использовании более простой технологии, которая соответствуют уровню квалификации рабочей силы в стране-реципиенте, по причине необходимости переквалификации местной рабочей силы, стоимости самой технологии, что негативно скажется на объемах экспорта иностранных филиалов. Кос- 
венное влияние требований местного компонента и передачи технологий в долгосрочном периоде - рост конкурентоспособности экспорта принимающего государства за счет распространения внешних эффектов ПИИ в случае эффективного налаживания связей иностранных компаний с национальными предприятиями, замещение импорта комплектующих и технологий, снижение стоимости экспорта за счет переориентации на более дешевые местные комплектующие.

е) Требования в отношении обязательной продажи определенной доли произведенной продукции на местном рынке способствуют притоку импортозамещающих ПИИ, однако дестимулируют экспорто ориентированные.

2. Требования эффективности, обусловливающие предоставление льгот и преференций. Данные требования будут иметь те же внешнеторговые эффекты, как и в случае необходимости их обязательного выполнения. Разница будет заключаться только в том, что предоставляемые льготы и преференции сами могут повлиять на эффективность деятельности иностранных компаний, что в свою очередь прямо или косвенно повлияет на их внешнеторговую деятельность, результирующий внешнеторговый эффект будет состоять из внешнеторговых эффектов требований к ПИИ и эффектов предоставленных льгот и преференций.

3. Стимулы и преференции для ПИИ:

а) Стимулье, влияющие на прибыльность экспортных операций (например, возврат пошлин на импортные товары, использованные для производства экспортных товаров), сокращают издержки производства, что стимулирует экспорт иностранных компаний, который, однако, как правило, сопровождается ростом импорта промежуточных товаров.

б) Стимуль, сокращающие переменные издержки производства (например, сокращение выплат на социальное страхование работников), способствуют расширению производства компаний с иностранными инвестициями. Внешнеторговые эффекты ПИИ будут зависеть от типа инвестиций.

в) Стимуль, привязанные к объему ПИИ, имеют внешнеторговые эффекты, схожие с предыдущими: они стимулируют приток ПИИ больший, чем тот, который необходим для удовлетворения внутреннего спроса.

г) Стимулы, дающчие привилегированный доступ на рынок, например, преференциальный доступ к государственным заказам, способствуют притоку импортозамещающих ПИИ, что сокращает импорт готовой продукции, однако приводит, как правило, к росту импорта инвестиционных и промежуточных товаров и услуг.

Косвенным внешнеторговым эффектом инвестиционных стимулов является переориентация ПИИ из стран и отраслей их эффективного применения в страны и отрасли с меньшей эффективностью использования ПИИ, что в итоге приведет к нерациональному распределению ресурсов в рамках всей мировой экономики, что в свою очередь будет непосредственно влиять на развитие международной торговли.

\section{ВЫВОДЫ}

Проведенное исследование позволяет сделать следующие ключевые выводы:

1) Одной из ключевых областей политики привлечения экспорто ориентированных ПИИ должно стать расширение доступа к импортным ресурсам за счет мер торговой политики за счет снижения таможенных пошлин на сырье и комплектующие. Необходимо найти баланс между наращиванием отечественного производственного потенциала, с одной стороны, и недопущением инвестиционного и торгового протекционизма, с другой. 
2) Доступ к основным рынкам сбыта, особенно к рынкам развитых стран, является необходимым условием привлечения ориентированной на экспорт деятельности иностранных компаний. В связи с этим важную роль при решении вопросов размещения экспортного производства играют РСТ и режимы преференциальной торговли.

3) Политика ограничения и политика стимулирования ПИИ в классическом их понимании также являются взаимозаменяемыми с позиции развития внешней торговли, что позволяет государственным органам принимающей страны маневрировать различными инструментами инвестиционной политики, исходя из соображений соотношения затрат и общественных выгод.

4) Таможенно-тарифные и нетарифные барьеры во внешней торговле могут снизить эффективность функционирования глобальных производственных сетей ТНК, в связи с чем в настоящее время торговая либерализация является важнейшей характеристикой благоприятного инвестиционного климата.

5) Внешнеторговая политика является более гибким и действенным инструментом реализации стратегии привлечения ПИИ с целью развития внешней торговли, нежели инвестиционная политика.

6) Внешнеторговая политика стран-доноров в значительно меньшей степени влияет на потоки ПИИ и их внешнеторговые эффекты для стран-реципиентов, нежели торговая политика самих принимающих стран, которая является критически важной для регулирования объемов и структуры потоков ПИИ.

\section{СПИСОК ИСПОЛЬЗОВАННЫХ ИСТОЧНИКОВ}

1. Ливенцев, Н. Н. Международное движение капитала: инвестиционная политика зарубежных стран / Н. Н. Ливенцев, Г. М. Костюнина. - М.: Экономисть, 2004. - 367 с.

2. World investment report 2012: Towards a new generation of investment policies. New York and Geneva: United Nations, UNCTAD, 2012. - 204 p.

3. Policy framework for investment: a review of good practices. Trade policy. Ch. 3. Paris: OECD, 2006. - Режим доступа: http://www.oecd.org - Дата достпупа: 21.02.2017.

4. Chakrabarti, A. The determinants of foreign direct investments: sensitivity analyses of cross-country regressions // Kyklos. - 2001. - Vol. 54, No. 1. - P. 89-114.

5. Elborgh-Woytek, K., Sadikov, A. Attracting and maximizing the benefits of foreign direct investment: the role of trade policy [Электронный ресурс]. - Режим доступа: www.carecprogram.org - Дата доступа: 21.02.2017.

6 . The relationship between trade and foreign direct investment: a survey. - Paris: OECD, 2002. -23 p.

7. Вдовин, И. А. Стратегия привлечения инвестиций / И. А. Вдовин. - М., 2008. $41 \mathrm{c}$.

8. Foreign direct investments for development: maximizing benefits, minimizing costs: overview. - Paris: OECD, 2002. -33 p.

9. Семак, Е. Современное представление о природе прямых иностранных инвестиций: интегрированный подход // Журнал международного права и международных отношений/ Е. Семак, И. Турлай. - 2009. - № 2. - [Электронный ресурс] - Режим доступа: http://www.beljournal.evolutio.info - Дата доступа: 21.02.2017.

10. Policy framework for investment: a review of good practices. Investment policy. Ch. 1. - Paris: OECD, 2006. - [Электронный ресурс] - Режим доступа: http://www.oecd.org - Дата доступа: 21.02.2017. 


\section{REFERENCES}

1. Liventsev, N. N. Mezhdunarodnoye dvizheniye kapitala: investitsionnaya poli-tika zarubezhnykh stran / N. N. Liventsev. G. M. Kostyunina. - M.: Ekonomist. 2004. - 367 s.

2. World investment report 2012: Towards a new generation of investment policies. New York and Geneva: United Nations. UNCTAD. 2012. - 204 p.

3. Policy framework for investment: a review of good practices. Trade policy. Ch. 3. Paris: OECD. 2006. - Rezhim dostupa: http://www.oecd.org - Datadostupa: 21.02.2017.

4. Chakrabarti, A. The determinants of foreign direct investments: sensitivity analyses of cross-country regressions // Kyklos. - 2001. - Vol. 54. No. 1. - P. 89-114.

5. Elborgh-Woytek, K., Sadikov, A. Attracting and maximizing the benefits of foreign direct investment: the role of trade policy. -URL: www.carecprogram.org (dataobrashcheniya: 21.02.2017).

6. The relationship between trade and foreign direct investment: a survey. - Paris: OECD. 2002. -23 r.

7. Vdovin, I. A. Strategiya privlecheniya investitsiy / I. A. Vdovin. - M.. 2008. - $41 \mathrm{s.}$

8. Foreign direct investments for development: maximizing benefits. minimizing costs: overview. - Paris: OECD. 2002. -33 r.

9. Semak, E. Sovremennoye predstavleniye o prirode pryamykh inostrannykh investitsiy: integrirovannyy podkhod // Zhurnal mezhdunarodnogo prava i mezhdunarodnykh otnosheniy/ E. Semak, I. Turlay. - 2009. - № 2. - Rezhim dostupa: http://www.beljournal.evolutio.info - Data dostupa: 21.02.2017.

10. Policy framework for investment: a review of good practices. Investment policy. Ch. 1. - Paris: OECD. 2006. - Rezhim dostupa: http://www.oecd.org - Data dostupa: 21.02.2017).

Статья поступила в редакциию 16 октября 2017 года. 